\title{
LAS PRUEBAS PERICIALES GENÉTICAS EN EL PROCESO PENAL EN MÉXICO EN EL MARCO LOS DERECHOS HUMANOS
}

\author{
THE GENETIC PERITIAL TESTS IN THE CRIMINAL PROCESS \\ IN MEXICO IN THE FRAMEWORK HUMAN RIGHTS
}

\section{AMALIA PATRICIA COBOS CAMPOS}

"El juez, antes de decidirse, tiene necesidad de una fuerza de carácter que puede faltar al abogado; debe tener el valor de ejercitar la función de juzgar, que es casi divina, aunque sienta dentro de si todas las debilidades y acaso todas las bajezas del hombre; debe tener el dominio de reducir a silencio una voz inquieta que le pregunta lo que habría hecho su fragilidad humana si se hubiese encontrado en las mismas condiciones del justiciable; debe estar tan seguro de su deber, que olvide, cada vez que pronuncia una sentencia, la amonestación eterna que le viene de la Montaña: No juzgar".

PIERO CALAMADREI ${ }^{2}$

\section{Resumen}

A raíz de la reforma constitucional en México, se ha gestado una fuerte polémica en cuanto a los alcances de la responsabilidad del juzgador en materia de derechos humanos, se ha hablado de un nuevo sistema de control difuso de la constitucionalidad, opinión que no ha sido avalada por la Suprema Corte de Justicia de la Nación, quien ha determinado que dicho control le corresponde en facultad exclusiva. Resulta, por

$1 \quad$ Miembro del Sistema Nacional de Investigadores Nivel I, doctora en derecho, profesora investigadora de la Facultad de Derecho de la Universidad|Autónoma de Chihuahua. pcobos@uach.mx

2 CALAMADREI, Piero: Elogio a los jueces escrito por un abogado. Sentis, Santiago y Medina, Isaac J. (trad.). Ed. Reus, Madrid, 2009. p. 55 
consecuencia, complejo para el juzgador ordinario medir cuáles son sus responsabilidades y alcances en la salvaguarda de los derechos humanos, en especial cuando se habla de pruebas genéticas que revisten ya de suyo un alto grado de complejidad en su ofrecimiento, admisión y desahogo. En la presente investigación se analiza desde una perspectiva teórica, las posturas doctrinales y jurisprudenciales al respecto, realizándose una amplia revisión bibliográfica, hemerográfica, jurisprudencial y de orden legislativo que sustentan las conclusiones, que nos permiten determinar que en México no existen parámetros debidamente regulados para la realización de las referidas probanzas bajo el esquema de una adecuada salvaguarda de los derechos humanos del imputado y que, en todo caso nuestra legislación parece inclinarse por lo que la doctrina ha denominado derecho penal del enemigo.

\title{
Palabras Clave
}

Proceso, derechos humanos, salvaguarda, pruebas genéticas, proceso.

\begin{abstract}
With the constitutional reform in Mexico, we encountering a strong controversy regarding the scope of the responsibility of the judge in the field of human rights. Has spoken of a new system of fuzzy control of constitutionality, but the Supreme Court of Justice of the nation, has not endorsed opinion, who has determined that such monitoring is in exclusive faculty. The ordinary judge it is consequently resort to measure what are their responsibilities and scope in the safeguarding of human rights, especially when we talk about genetic tests; that are already of a high degree of complexity in its offering, admission and relief of his. This paper analyzes from a theoretical perspective, the doctrinal and jurisprudential positions. In this regard, effected an extensive literature review about scholar's opinions, hemerographic, jurisprudential and legislative underpinning the conclusions. Those conclusions allow us to determine that in Mexico, there are no parameters properly regulated for the realization of the concerned evidence under the scheme of an adequate safeguard of the accused rights and that in any case our legislation seems to prefer that the doctrine has called enemy criminal law.
\end{abstract}




\section{Keywords}

Procedure, human rights, safeguard, genetic tests.

\section{Introducción.}

En México, derivado de la reforma constitucional gestada en materia de derechos humanos en el 2011, se dejaron atrás las complejas discusiones sobre la utilización de manera poco técnica del término de garantías individuales para designar los derechos fundamentales, confundiendo los mecanismos de tutela con la materia de esta, el propio derecho a proteger.

Una vez que se modifica el artículo primero constitucional y se añade el rubro "de los derechos humanos y sus garantías", la añeja discusión queda sin materia y es claro que el legislador mexicano se decanta por el uso de derechos humanos que es, como sabemos, mucho más amplio, ubicando las garantías en el lugar que les compete ocupar, como mecanismos procesales de protección.

Empero, de ello se derivan nuevas problemáticas, quizá más espinosas que las antes articuladas. Del texto constitucional, en particular de la nueva redacción y su exigencia de aplicar los instrumentos internacionales al proceso ordinario, se ubica al operador judicial de este orden en una situación de indefinición en cuanto al alcance y grado de su responsabilidad en la salvaguarda de los derechos humanos, responsabilidad que no se encuentra claramente acotada en nuestra carta fundamental y que ha generado tanto en la doctrina como en las resoluciones judiciales de tribunales internos y transnacionales álgidos puntos de discusión.

Esto es así, porque al consagrar nuestra carta fundamental que se tutelan tales derechos, establece una obligación a cargo de los jueces ordinarios de guarecerlos, encontrando este un panorama de altas responsabilidades en este sentido. En materia procesal, ello se vuelve más complejo aún, ya que existen aspectos en el proceso contemporáneo que se encuentran en bastante imprecisión, ya que los avances técnicos han superado en mucho a los legislativos.

Como consecuencia de lo anterior, la acotada -por la Corte- facultad interpretativa del juez para llenar las lagunas existentes se torna una herramienta esencial e ineludible y en el tema que nos ocupa, de un ejercicio no solo laborioso, sino resbaladizo y bastante complicado; ante ello el juzgador se enfrenta, además, como conocedor del derecho, pero ajeno a ciertos conocimientos científicos, ya que no cuenta con 
conocimientos especializados en la materia. Ya la doctrina se ha ocupado de tales cavilaciones, buscando las salidas que permitan el equilibrio entre la justeza del proceso y los derechos humanos enfrentados en él en cada caso particular, pero más importante aún, busca dilucidar los alcances de la responsabilidad del juez en materia de pruebas científicas y su debida valoración. ${ }^{3}$

No parece haber reglas universales aplicables a todos los presupuestos, $\mathrm{y}$ en cuanto a la prueba pericial genética, es frecuente que se actualice la colisión de derechos en la práctica de la misma. Encontramos, igualmente, las álgidas discusiones que surgen por la práctica forzosa de dichas pruebas, aún a las víctimas en materia penal y a terceros en varias áreas incluidas esta última y la familiar.

Presentamos en consecuencia un panorama doctrinario, legislativo y jurisprudencial del tema -aunque acotado por la brevedad del espacio- que nos permite concluir la indefinición que al respecto existe en México y los problemas que ello acarrea al proceso y al operador judicial ordinario, ante una legislación incompleta y en algunos casos plagada de antinomias y una escasa construcción jurisprudencial en la materia y sin que la promulgación del Código Nacional de Procedimientos Penales haya podido resolver tales cuestiones visto su contenido al respecto que también comentaremos y sin demeritar los avances que el mismo contiene.

\section{El contexto procesal de la prueba contemporánea.}

Los nuevos tiempos exigen, sin duda, nuevos retos, y el proceso no es la excepción, encontramos un movimiento mundial que busca ajustarlo a los requerimientos de esta corriente renovadora, que ha acarreado la mayor cantidad de reformas procesales de que se tenga memoria a nivel mundial, aunada a la jurisprudencia de tribunales transnacionales que igualmente transforman al derecho interno y lo obligan a reflexiones y variaciones jurídicas profundas. Cuestiones otrora cerradas como lo son el equilibrio

3 Véase al respecto: FIGUEROA, Carmen, (Coord.): La prueba pericial científica. Instituto Universitario de Investigación en Ciencias Policiales/Universidad de Alcalá, Madrid, 2012. p. 437 ss.; FERRER Jordi, et al: Estudios sobre la prueba. Fontamara, $3^{\mathrm{a}}$ Ed., México, 2016, p. 200 ss.; RAMÍREZ, Diana María: "Los límites constitucionales a los poderes de oficio que tiene el juez sobre la prueba". En: Temas Procesales, No. 27, segundo semestre de 2011. COMLIBROS, Medellín. pp. 101-134; COBOS, Amalia Patricia: "Aspectos epistemológicos de las pruebas periciales genéticas". En: Estudio Comparado entre España y México. Universidad Autónoma de Chihuahua, 2015; entre muchos otros. 
procesal y la carga de la prueba, son puestos en tela de juicio y algunas veces hasta trastocados.

Recordemos que Devis Echandía definió a la carga de la prueba como "una noción procesal que contiene la regla del juicio, por medio de la cual se le indica la juez como debe fallar cuando no encuentre en el proceso pruebas que le den certeza sobre los hechos que deben fundamentar su decisión, e indirectamente establece a cuál de las partes le interesa la prueba de tales hechos, para evitarse las consecuencias desfavorables." ${ }^{\prime}$ No pretendemos enzarzarnos en el análisis de esta figura y todas las corrientes jurídicas que la explican, ya que es ajeno a las pretensiones del presente trabajo y por ello, nos limitamos a enunciar tal concepción que nos parece pertinente para clarificar contenidos.

Pereira Campos, ${ }^{5}$ acertadamente ha dicho que: ante la crisis del sistema tradicional de carga de la prueba, especialmente en situaciones en las que se presentan asimetrías profundas entre las partes y se producen dificultades para que una de ellas obtenga la prueba necesaria para el proceso, debido a la inactividad de su contrario, algunas legislaciones han regulado expresamente este instituto o, aún sin norma expresa, ha sido desarrollado por la jurisprudencia. Si bien existe doctrina al respecto desde los clásicos autores del derecho procesal, ha sido en los últimos 30 años que en la práctica se ha desarrollado con más vigor $[. .$.$] debe señalarse que el riesgo$ está en su utilización abusiva y sorpresiva por el tribunal. [...] la doctrina trabaja en fórmulas que permitan el adecuado control de las partes respecto a la utilización de este instrumento por el tribunal, por ejemplo, mediante la imposición por ley del deber del juez de dar un aviso a las partes de que aplicará las cargas dinámicas [...] o la necesidad de que la parte que quiere servirse de las cargas dinámicas utilice previamente en forma diligente las herramientas que la ley le da para obtener la prueba

Igualmente, en algunos supuestos, se ha llegado a pretender que resulta válido sacrificar derechos en aras de la seguridad jurídica, y así, se justifican figuras como el arraigo constitucional, que, pese a las argumentaciones en contrario, estimamos absolutamente vulneratorio de la presunción de inocencia constitucionalmente protegida.

4 DEVIS ECHANDÍA, Hernando, Teoría general de la prueba judicial, t. I, $5^{\text {a }}$ Ed. Editorial ABC, Bogotá, 1996. p. 426.

5 PEREIRA CAMPOS, Santiago, "Desafíos y riesgos del derecho procesal contemporáneo", Instituto Chileno de Derecho Procesal, diciembre de 2012, disponible en: http://www.ichdp.cl/desafios-y-riesgos-del-derecho-procesal-contemporaneo/ 
En cuanto a la prueba, su papel protagónico en el proceso es ineludible, empero su percepción y construcción se ajustan a los nuevos tiempos del derecho. Midón afirma que aún en los procesos que competen al derecho privado, ya no está en juego únicamente el interés de los justiciables, sino que existe además el interés público en preservar el estado de derecho a través de la recta aplicación de éste, la cual depende del nexo relacional entre los puntos de la sentencia y la verdad real de los hechos materia de la litis, cuyo acceso al proceso se da solo a través de la prueba. ${ }^{6}$

En torno a la prueba, en su papel de necesariedad en el proceso, existen múltiples cuestiones que han generado que la doctrina jurídica construya a su periplo toda una teoría de la prueba, en cuya existencia no todos coinciden, pero que quienes la conciben, como es el caso de Alsina, ${ }^{7}$ han estimado que su existencia permite "establecer el modo como el juez va adquiriendo conocimiento de las cosas; explica la formación lógica de los distintos medios de prueba, y la vinculación que entre ellos existe, base de la prueba compuesta, suministra por último el criterio para la valoración de la prueba en la sentencia."

Pallares conceptúa a la prueba como la "justificación de la veracidad de los hechos en que se fundan las pretensiones y los derechos de las partes en un proceso instaurado ante un órgano que desempeñará una función jurisdiccional desde el punto de vista material."

Gómez del Castillo y Gómez, ${ }^{9}$ por su parte, ha analizado la terminología que se ha acuñado al diferenciar lo que la doctrina llama nuevos medios de prueba y nos dice que estos pueden considerarse como "aquellos que no aparecen relacionados en las antiguas leyes de enjuiciamiento (o, con mayor propiedad, aquellos que no pudieron estar en la mente del legislador al tiempo de promulgarse dichas leyes) y que son propiciados por los avances científicos o tecnológicos".

Nos enfocamos, en consecuencia, hacia las pruebas científicas, término bajo el cual se engloban todas aquéllas que se sustentan en los

6 MIDÓN, Marcelo Sebastián: Derecho probatorio. Parte general, v. I. Ediciones Jurídicas Cuyo, 2007, Mendoza. p. 215

7 ALSINA, Hugo Tratado teórico práctico del derecho procesal civil y comercial, t. III. EDIAR, Buenos Aires, 1961. p.227.

8 Pallares, Eduardo, citado por ARELLANO GARCÍA: Derecho Procesal Civil. Porrúa, México, 1998. p. 221.

9 GÓMEZ DEL CASTILLO y GÓMEZ, Manuel M.: "Aproximación a los nuevos medios de prueba en el proceso civil”. En: Derecho y Conocimiento, v. I. Universidad de Huelva, 2001. pp. 77-90. 
avances sin precedentes de la propia ciencia, y a las que la doctrina procesal concibe como "el medio de prueba a través del cual se pretende acreditar al juzgador la veracidad de las afirmaciones realizadas, utilizando mecanismos desarrollados por la ciencia o la técnica que funcionan mediante procedimientos físicos o químicos y que conservan memoria de hechos o actos en forma diferente del lenguaje escrito."

Las pruebas científicas, asegura de Luca," $\sin$ duda alguna "han incrementado las posibilidades de averiguar la verdad, pero su valor en el proceso depende de otras circunstancias. La primera es que el perito comunique al juez, en los términos más rigurosos y claros posibles, el margen de incertidumbre del informe que emite. No obstante, segunda circunstancia, es al juez a quien corresponde verificar, sin influencia de criterio extra-científicos, la validez de las pruebas y atribuirles un valor en la decisión que debe adoptar. Para eso se considera obligatoria una cierta formación y especialización en la materia tanto del experto como del juez."

Es claro que a la luz de los avances científicos se han tenido que replantear algunos conceptos tradicionales a efecto de dar cabida a estas nuevas formas de probar que debemos reconocer han traído un mayor grado de certeza al proceso, pero que también han generado otros nuevos desafíos para poder establecer criterios de fiabilidad y certeza a su vera.

Cabe igualmente conceder al Código Nacional de Procedimientos Penales el mérito de distinguir, como ha pretendido hacerlo la doctrina jurídica de tiempo atrás, entre datos de pruebas, medios de prueba y prueba propiamente dicha, así el ordenamiento determina: artículo 261. Datos de prueba, medios de prueba y pruebas.

"El dato de prueba es la referencia al contenido de un determinado medio de convicción aún no desahogado ante el Órgano jurisdiccional, que se advierta idóneo y pertinente para establecer razonablemente la existencia de un hecho delictivo y la probable participación del imputado. Los medios o elementos de prueba son toda fuente de información que permite reconstruir los hechos, respetando las formalidades procedimentales previstas para cada uno de ellos. Se denomina prueba a todo conocimiento

10 CONTRERAS VACA, Francisco José: Derecho procesal civil, v. I. Oxford, México, 1999.p. 147

11 LUCA, Stefano de, NAVARRO, Fernando y CAMERIERE, Roberto: "La prueba pericial y su valoración en el ámbito judicial español”. En: Revista Electrónica de Ciencia Penal y Criminología, [en linea], No. 15, 2013, disponible en: http://criminet.ugr.es/recpc/15/ recpc15-19.pdf. 
cierto o probable sobre un hecho, que ingresando al proceso como medio de prueba en una audiencia y desahogada bajo los principios de inmediación y contradicción, sirve al Tribunal de enjuiciamiento como elemento de juicio para llegar a una conclusión cierta sobre los hechos materia de la acusación."

Esta diferenciación resulta importante, ya que en México ha habido siempre gran confusión en el uso de dicha terminología, que se inserta de manera indistinta en los ordenamientos y los fallos judiciales, así al analizar la prueba materia de nuestro estudio estaremos frente a las dos últimas connotaciones, que es cuando existe intervención del juzgador tano para su desahogo como para su valoración, y es ahí donde surgen los puntos álgidos materia de la discusión en el marco de los derechos humanos.

\section{La responsabilidad del juzgador ordinario en la tutela de los derechos humanos y las pruebas genéticas en el proceso.}

Las pruebas genéticas, aun cuando no existe un consenso universal al respecto en la doctrina jurídica, son mayoritariamente consideradas dentro del rubro de las pruebas periciales, las que por su parte, siguiendo a González Pillado e Iglesias Canle, ${ }^{12}$ las consideraremos como un medio de prueba en virtud del cual una persona ajena al proceso, con conocimientos especializados o técnicos de los que el órgano jurisdiccional carece, los aporta al mismo, para que el juez pueda valorar mejor la naturaleza de los elementos o hechos de prueba, sin olvidar que esa prueba, debe referirse precisamente a conceptos, juicios y máximas de experiencia propias de un saber especializado.

Los elementos personales de dicho medio de convicción lo son, como es de explorado derecho, los peritos, entendidos como aquella persona física que es llamada al proceso para informar al juzgador sobre hechos cuya apreciación se relaciona con conocimientos especializados que posee sobre alguna ciencia o arte. ${ }^{13}$

En cuanto a su naturaleza o no, como prueba, como es consabido, existen múltiples corrientes que analizan esta, empero dirimiremos esta controversia mediante un criterio sostenido por nuestro máximo tribunal a

12 GONZÁLEZ PILLADO, Esther e IGLESIAS CANLE, Inés: "La prueba pericial en la nueva ley de enjuiciamiento civil”. En: Revista Xurídica Galega, No. 27, 2000. pp. $307-$ 344.

13 CONTRERAS VACA, ob. cit., p. 149. 
efecto de no dispersarnos de los aspectos torales del presente estudio, así la corte ha determinado que el dictamen pericial es: ${ }^{14}$

[U]na prueba sui generis y cuya apreciación no puede hacerse sino siguiendo los principios que le son inherentes. En otro tiempo ya los doctores quisieron considerar a los peritos como especie de testigos. [...] El Juez basa su sentencia en la respuesta del perito a la pregunta prejudicial, a menos que exista un justo motivo para dudar que aquélla sea cierta y fundada. Examinando más a fondo los motivos de la confianza del juez cuando de este modo abandona la dirección de su convicción a las palabras del perito [...] el perito tiene derecho a la confianza del Juez, dentro de los límites de su profesión y de sus declaraciones científicas, cuando posee los conocimientos especiales requeridos y sabe discernir los caracteres facultativos, en los hechos de su competencia o echa mano de los medios científicos $[\ldots]$ para fundar la verdad $[\ldots]$

En México el ordenamiento procesal que con mayor profusión se ocupa de la prueba genética lo es el Código Nacional de Procedimientos Penales, que en cuanto a las periciales en lo conducente determina que estas podrán ofrecerse: artículo 368. Prueba pericial.

"Podrá ofrecerse la prueba pericial cuando, para el examen de personas, hechos, objetos o circunstancias relevantes para el proceso, fuere necesario o conveniente poseer conocimientos especiales en alguna ciencia, arte, técnica u oficio."

El ordenamiento no hace alusión expresa a pruebas genéticas, pero si alude a las pruebas biológicas a las que la propia legislación y los estudiosos del tema han estimado como sinónimo de pruebas genéticas, a vía de ejemplo baste reproducir lo que al respecto ha dicho Martín Alonso, ${ }^{15}$ al considerar que la prueba genética consiste en:

[L]a comparación entre una muestra dubitada -aquella que en principio no se sabe a qué sujeto pertenece-y otra indubitada-obtenida de la persona sospechosa-. Si ambas coinciden en sus resultados, este medio probatorio puede servir al referido objeto de acreditación de la intervención de alguien en el hecho criminal investigado.

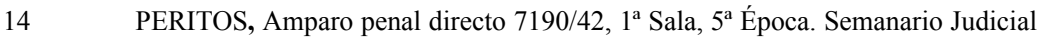
de la Federación, T. LXXV.

15 MARTÍN ALONSO, Francisco: "Recogida de muestras biológicas para la obtención de un perfil ADN, desde la perspectiva policial". En: Noticias Jurídicas [en línea], mayo de 2014, disponible en: http://noticias.juridicas. Com /articulos/65-Derecho-ProcesalPenal/201405-recogida-de-muestras-biologicas.htm. 
Las pruebas a que atiende nuestro estudio requieren para su realización de lo que la doctrina jurídica ha denominado intervención corporal, la cual podemos enunciar como "aquellas medidas de investigación que dentro del proceso tienen por objeto el cuerpo de una persona, y cuya finalidad puede ser tanto la búsqueda del cuerpo del delito como concretar aspectos relativos a la salud física o psíquica de una persona"; ${ }^{16}$ por lo que ya más concretamente dirigido al tema, encontramos que el Código Nacional de Procedimientos Penales establece regulación sobre aquellas intervenciones personales que se requieran, ${ }^{17}$ las que permite incluso desde la fase de investigación y relacionadas con toma de muestras corporales, así se desprende del contenido de los artículos 269 y 270 del ordenamiento en cita, que son del siguiente tenor literal: artículo 269. Revisión corporal.

"Durante la investigación, la Policía o, en su caso el Ministerio Público, podrá solicitar a cualquier persona la aportación voluntaria de muestras de fluido corporal, vello o cabello, exámenes corporales de carácter biológico, extracciones de sangre u otros análogos, así como que se le permita obtener imágenes internas o externas de alguna parte del cuerpo, siempre que no implique riesgos para la salud y la dignidad de la persona.

Se deberá informar previamente a la persona el motivo de la aportación $\mathrm{y}$ del derecho que tiene a negarse a proporcionar dichas muestras. En los casos de delitos que impliquen violencia contra las mujeres, en los términos de la Ley General de Acceso de las Mujeres a una Vida Libre de Violencia, la inspección corporal deberá ser llevada a cabo en pleno cumplimiento del consentimiento informado de la víctima y con respeto de sus derechos.

Las muestras o imágenes deberán ser obtenidas por personal especializado, mismo que en todo caso deberá de ser del mismo sexo, o del sexo que la persona elija, con estricto apego al respeto a la dignidad y a los derechos humanos y de conformidad con los protocolos que al efecto expida la Procuraduría. Las muestras o imágenes obtenidas serán analizadas y dictaminadas por los peritos en la materia". ${ }^{18}$

Artículo 270. Toma de muestras cuando la persona requerida se niegue a proporcionarlas.

16 GONZÁLEZ-CUÉLLAR SERRANO, Nicolás: Proporcionalidad y derechos fundamentales en el proceso penal. Colex Editorial, Madrid, 1990. p. 17.

17 Congreso de la Unión, Código Nacional de Procedimientos Penales, publicado en

el Diario Oficial de la Federación el 5 de marzo de 2014; última reforma publicada D.O.F 2912-2014, disponible en: http://www.diputados.gob.mx/LeyesBiblio/pdf/CNPP_250618.pdf,. 
"Si la persona a la que se le hubiere solicitado la aportación voluntaria de las muestras referidas en el artículo anterior se negara a hacerlo, el Ministerio Público por sí o a solicitud de la Policía podrá solicitar al Órgano jurisdiccional, por cualquier medio, la inmediata autorización de la práctica de dicho acto de investigación, justificando la necesidad de la medida y expresando la persona o personas en quienes haya de practicarse, el tipo y extensión de muestra o imagen a obtener. De concederse la autorización requerida, el Órgano jurisdiccional deberá facultar al Ministerio Público para que, en el caso de que la persona a inspeccionar ya no se encuentre ante él, ordene su localización y comparecencia a efecto de que tenga verificativo el acto correspondiente.

ElÓrgano jurisdiccional al resolver respecto de la solicitud del Ministerio Público, deberá tomar en consideración el principio de proporcionalidad y motivar la necesidad de la aplicación de dicha medida, en el sentido de que no existe otra menos gravosa para la persona que habrá de ser examinada o para el imputado, que resulte igualmente eficaz e idónea para el fin que se persigue, justificando la misma en atención a la gravedad del hecho que se investiga.

En la toma de muestras podrá estar presente una persona de confianza del examinado o el abogado Defensor en caso de que se trate del imputado, quien será advertido previamente de tal derecho. Tratándose de menores de edad estará presente quien ejerza la patria potestad, la tutela o curatela del sujeto. A falta de alguno de éstos deberá estar presente el Ministerio Público en su calidad de representante social.

En caso de personas inimputables que tengan alguna discapacidad se proveerá de los apoyos necesarios para que puedan tomar la decisión correspondiente.

Cuando exista peligro de desvanecimiento del medio de la prueba, la solicitud se hará por cualquier medio expedito y el Órgano jurisdiccional deberá autorizar inmediatamente la práctica del acto de investigación, siempre que se cumpla con las condiciones señaladas en este artículo."19

Ambos numerales merecen una adecuada reflexión y análisis, en especial el último citado; en principio en el artículo 269, no sólo al ministerio público, sino también a la policía para obtener la aportación de muestras de fluido corporal, sin tomar en consideración los requerimientos especiales que ese tipo de muestras conllevan, toda vez que el numeral no requiere la 
presencia de especialista alguno, sino que se refiere a que la propia policía y el ministerio público las pueden no solo solicitar sino también obtener. A nuestro juicio la construcción del artículo es desafortunada en este sentido, ya que bastaban añadir que debería solicitar el apoyo de los especialistas del ramo, no solo a efecto de proteger los derechos sino incluso en aras de la obtención de pruebas debidamente realizadas, no obsta a lo comentado el que en el párrafo tercero añada que la muestra debe ser obtenida por personal especializado, toda vez que al estar unido a otro párrafo que alude claramente a las mujeres víctimas de violencia y no se aplica en general a todos, sino que es evidente que el legislador se centra en estas víctimas para una tutela especial.

Cabe resaltar que en el precepto en cuestión se habla de la voluntariedad, pero el diverso numeral 270, ya agrega la vis compulsiva para la obtención de los datos de prueba, caso en el que se requiere la autorización judicial para su práctica, más la misma no se lleva a cabo frente al referido operador judicial, sino por el ministerio público, según se desprende del contenido del precepto, ya que en ninguna parte del código en estudio se autoriza al juez en el desahogo de probanzas a la vis compulsiva, del precepto deriva que esto solo puede realizarse en la fase de investigación lo que parece un contrasentido.

Otro aspecto esencial, es que no se establece cuáles son los mecanismos que se autorizan para obtener dicha muestra forzosa, ni tampoco se determina excepción en cuanto a las personas a obligar, de lo que podemos inferir que se puede aplicar al imputado, a la víctima e incluso a terceros ya que el artículo alude a cualquier persona, con una discrecionalidad que podría parecer ajena a las facultades de un órgano policial e incluso ministerial, puesto que solo en el caso de la negativa se requiere la autorización del juzgador.

Pero por si esto fuera poco, si acudimos al diverso artículo 252 es aún más confuso, porque pareciera excluir de la autorización judicial al imputado y a la víctima cuando en lo conducente dice: artículo 252. Actos de investigación que requieren autorización previa del Juez de control. "Con excepción de los actos de investigación previstos en el artículo anterior, requieren de autorización previa del Juez de control todos los actos de investigación que impliquen afectación a derechos establecidos en la Constitución, así como los siguientes: [...] 
IV. La toma de muestras de fluido corporal, vello o cabello, extracciones de sangre $u$ otros análogos, cuando la persona requerida, excepto la víctima u ofendido, se niegue a proporcionar la misma;

V. El reconocimiento o examen físico de una persona cuando aquélla se niegue a ser examinada [...]"

Como vemos la falta de técnica en la redacción de los preceptos crea situaciones de indefinición, ya que, el numeral 269 claramente alude al imputado y a la víctima, en el caso del primero con una redacción por demás desafortunada ya que pareciera no conceder al imputado el estatus de persona.

Es este el punto central de la discusión en materia de derechos humanos en cuanto a la realización y aportación al proceso de tales pruebas, en principio, la aplicación forzosa al imputado y sin la necesaria presencia de su defensor, ${ }^{20}$ vulnera el contenido del propio ordenamiento ya que el diverso numeral 113 que contiene los derechos del imputado y más concisamente la fracción VI que dice que tienen derecho "a no ser sometido en ningún momento del procedimiento a técnicas ni métodos que atenten contra su dignidad, induzcan o alteren su libre voluntad", ${ }^{21}$ cabría preguntarse entonces cuál precepto va a aplicar el juzgador ordinario.

Otra legislación a analizar en la materia es la familiar, ya que en ella se encuentra otro de los problemas críticos en lo relativo a estas pruebas, en particular en la búsqueda del derecho a la identidad de los menores, acudiremos, en consecuencia, al Código Federal de Procedimientos Civiles, visto que en México no existe una legislación familiar diversificada de dicho ordenamiento en materia federal, si bien si la hay en algunas entidades federativas. En lo relativo el ordenamiento de referencia determina que procede la prueba pericial en los términos del numeral 143 cuando se trate de "cuestiones de un negocio relativas a alguna ciencia o arte, y en los casos en que expresamente lo prevenga la ley", ${ }^{22}$ las misma se realizan a petición

$20 \quad$ Pese a que el artículo 113 del Código Nacional de Procedimientos Penales, fracción IV, le concede tal derecho cuando determina: "A estar asistido de su Defensor al momento de rendir su declaración, así como en cualquier otra actuación y a entrevistarse en privado previamente con él". Ello por si hubiera duda de la propia protección que la constitución le concede en tal sentido.

21 Código Nacional de Procedimientos Penales, artículo 113, fracción VI.

22 Código Federal de Procedimientos Civiles, publicado en el Diario Oficial de la Federación el 24 de febrero de 1943, última reforma publicada D.O.F 09-04-2012. 
de parte y nada dice en relación con pruebas científicas, salvo el contenido del artículo 188 que alude vagamente a los descubrimientos de la ciencia; un examen del Código Civil Federal tampoco nos trae mucha claridad al tema, si partimos de que ni menciona tales pruebas y la vaguedad con que construye su factibilidad en el artículo 341, deviene en la irrelevancia dando prioridad a otros medios de convicción ya que en lo conducente dice:

Artículo 341. "A falta de actas o si éstas fueren defectuosas, incompletas o falsas, se probará con la posesión constante de estado de hijo nacido de matrimonio. En defecto de esta posesión son admisibles para demostrar la filiación todos los medios de prueba que la ley autoriza, pero la testimonial no es admisible si no hubiere un principio de prueba por escrito o indicios o presunciones resultantes de hechos ciertos que se consideren bastante graves para determinar su admisión".

En este sentido son mucho más afortunadas las redacciones de los ordenamientos de las entidades federativas, que en su mayoría aluden mínimo a pruebas científicas unas y a biológicas otras, como el Código Civil para el Distrito Federal, ${ }^{23}$ o el de Procedimientos Civiles del Estado de Tabasco, ${ }^{24}$ entre otros, ya sea en sus ordenamientos civiles o en los familiares ${ }^{25}$ quienes ya cuentan con ellos; empero, no realizaremos un estudio comparado de tales legislaciones por ser ajeno al tema que nos ocupa, indicando únicamente la situación prevaleciente en este sentido desde un punto de vista legislativo

23 El artículo 341 en lo conducente dice: "A falta de acta o si ésta fuere defectuosa, incompleta o falsa, se probará con la posesión constante de estado de hijo. En defecto de esta posesión, son admisibles para demostrar la filiación todos los medios de prueba que la ley autoriza, incluyendo aquellas que el avance de los conocimientos científicos ofrece [...].

24 En su artículo 514, al regular las particularidades de los juicios de paternidad y filiación determina en su fracción: "VII. El juzgador podrá admitir alegaciones y pruebas de las partes, aunque se presenten fuera de plazo; Inclusive el análisis biológico molecular de la caracterización del ácido desoxirribonucleico de las células del demandado y el actor, cuyos materiales genéticos se obtendrán en presencia del juzgador. El costo de dicha prueba pericial, realizado por persona autorizada para tales efectos por la Secretaria de Salud, será a cargo del padre biológico cuando éste resulte serlo, en caso contrario será por cuenta del oferente."

25 Por ejemplo, el Código Familiar del Estado de Sonora alude a las pruebas biológicas en varios preceptos entre ellos el Artículo 264 que determina en lo conducente: "El reconocimiento es anulable si se prueba que el que lo hizo sufrió error, engaño o violencia, pero aun así deberán realizarse de oficio las pruebas biológicas previstas por este código. [...]". Lo particular del ordenamiento es que ordena las pruebas de oficio no a petición de parte. 
Luego entonces, ante tal legislación, que únicamente hemos analizado de forma somera, en vía de ejemplo, podemos establecer el grado de complejidad para el juzgador al momento de tutelar los derechos humanos y decidir sobre la práctica de tales diligencias, es evidente que no existe claridad y que la vaguedad como es sabido puede derivar en vulneración de derechos.

Cabe, en consecuencia, acudir a los criterios jurisprudenciales para intentar a través de ellos construir un panorama más acorde al respeto irrestricto de los derechos humanos que debe privilegiarse en cualquier estado democrático contemporáneo.

La mayor complejidad del problema, como es lógico suponer, se genera en materia penal, ya que no existe ninguna legislación que aluda a practicar forzosamente la prueba en materia civil o familiar, y en cuanto a las consecuencias de la negativa y a la presunción de certeza de los hechos materia del juicio de filiación cuando el demandado se niega a practicarse la prueba de $\mathrm{ADN}$, la Corte lo resolvió en una contradicción de tesis desde el 2005 en la jurisprudencia que bajo el rubro "Juicios de paternidad. En los casos en que a pesar de la imposición de medidas de apremio los presuntos ascendientes se niegan a practicarse la prueba pericial en materia de genética $(\mathrm{ADN})$, opera la presunción de la filiación controvertida (legislaciones de nuevo león y del estado de México", ${ }^{26}$ que por la extensión misma del rubro no requiere mayor explicación y a cuyo derredor se han seguido edificando criterios que tienden a proteger el interés superior del menor y su derecho a la identidad, privilegiándolo sobre los derechos a la intimidad, privacidad e integridad del presunto padre, como se desprende de la diversa contradicción de tesis 50/2011, que en lo conducente dice:

“[...] Sin lugar a dudas, debe prevalecer el interés del niño a conocer su identidad y a ejercer los derechos derivados de ésta, tales como tener una familia y que sus ascendientes satisfagan sus necesidades de alimentación, salud, educación y sano esparcimiento. En efecto, constituye un interés primordial del Estado que se garantice el pleno desarrollo del menor, por lo

26 Primera Sala de la Suprema Corte de Justicia de la Nación, al resolver la contradicción de tesis 154/2005-PS de la que derivó la jurisprudencia 1a./J. 101/2006, publicada en el Semanario Judicial de la Federación y su Gaceta, Novena Época, Tomo XXV, marzo de 2007, página 111 
que el interés de preservar la estabilidad de un matrimonio no puede estar por encima del derecho a la identidad del niño. $[\ldots]^{27}$

En cuanto a la negativa del presunto hijo o quienes le representan a practicarse la prueba la corte ha determinado en el mismo sentido que existe la presunción de ser ciertos los hechos manejados por su contraparte, así ha establecido que:

"[C]uando en un juicio de desconocimiento de paternidad se ofrece la prueba pericial en genética molecular, y el menor (a través de quien lo tiene bajo su patria potestad y lo representa $)^{28}$ se niega a que se le practiquen los exámenes correspondientes, no puede obligarse a practicar en su persona dicha probanza, pero en tal supuesto deben tenerse por ciertos los hechos narrados por su contraparte, salvo prueba en contrario..$^{29}$

La Corte en México no se ha pronunciado al respecto en cuanto al imputado. Existen algunos criterios, verbigracia, respecto de la víctima cuando esta se niega a proporcionar material genético tratándose del delito de violación en lo conducente resolvió:

"Si durante la instrucción el defensor del acusado solicitó la práctica de la prueba pericial en materia genética (ADN) con el propósito de desvirtuar la afirmación de la víctima en el sentido de que como resultado de la cópula que le impuso el inculpado quedó embarazada, y tal petición fue denegada por el Juez de primera instancia con base en la simple oposición de la pasivo, resulta inconcuso que dicha determinación afecta la garantía de defensa del procesado, [...] En consecuencia, [...] lo procedente es conceder el amparo para el efecto de que se ordene la reposición del procedimiento con el fin de que el Juez de primera instancia admita y desahogue esa prueba, apercibiendo a la ofendida, [...] de que para el caso de oponerse injustificadamente a ello, se presumirá la inocencia del

27 CONTRADICCIÓN DE TESIS 50/2011. ENTRE LAS SUSTENTADAS POR LOS TRIBUNALES COLEGIADOS PRIMERO Y SEGUNDO, AMBOS EN MATERIA CIVIL DEL SÉPTIMO CIRCUITO. Número de registro: 23101 Novena Época, Primera Sala, Semanario Judicial de la Federación y su Gaceta, Tomo XXXIV, septiembre de 2011, p. 664. $28 \quad$ En el original

29 PRUEBA PERICIAL EN GENÉTICA MOLECULAR. CUANDO SE OFRECE EN EL JUICIO DE DESCONOCIMIENTO DE PATERNIDAD Y EL MENOR SE NIEGA A QUE SE LE PRACTIQUEN LOS EXÁMENES CORRESPONDIENTES, DEBEN TENERSE POR CIERTOS LOS HECHOS NARRADOS POR SU CONTRAPARTE, SALVO PRUEBA, AD 226/2006, Tercer Tribunal Colegiado del Primer Circuito, 13 de julio de 2006. 
inculpado; conclusión a la cual se arriba después de interpretar, a la luz del principio de igualdad procesal y del de equidad $[\ldots] .{ }^{30}$

En virtud de que nuestro máximo tribunal no se ha pronunciado al respecto acudimos a la jurisprudencia del Tribunal Supremo Español que al respecto ha establecido: "La sumisión a una prueba que supone una invasión de la integridad corporal del sospechoso, como la que supone la extracción de sangre o de cualquier otro tejido o sustancia corporal para realizar un análisis científico, puede ofrecer colisiones con el respeto a la integridad corporal y con el derecho que tiene todo acusado, a no colaborar con las autoridades encargadas de la investigación y de no facilitar pruebas que pudieran incriminarle. Esta posibilidad ha abierto un debate interesante, desde el punto de vista de la salvaguarda de los derechos de toda persona involucrada en un proceso penal y ha sido resuelto, de forma diferente, por los diversos sistemas procesales de nuestro común acervo jurídico y cultural. Desde nuestra perspectiva constitucional y jurisprudencial, se ha dicho por esta Sala, que la prueba del ADN no puede ser admitida como válida, cuando la decisión de la intervención no está amparada por una resolución judicial, debidamente razonada y escrupulosamente proporcional a la naturaleza del delito perseguido y a los medios disponibles para la investigación. Según la opinión mayoritaria de la doctrina, avalada por decisiones del Tribunal Constitucional (STC 29 de Noviembre de 1984 y 19 de Febrero de 1992) no es admisible la utilización de fuerza física o cualquier otra actitud compulsiva o coactiva sobre la persona, para que ésta se preste a la práctica de la prueba, decidida por la autoridad judicial, debiendo respetarse la autonomía de la decisión por parte del afectado". ${ }^{31}$

De la jurisprudencia del Tribunal Supremo Español podemos desprender varias cuestiones, en principio, que cualquier intervención corporal al imputado debe estar sustentada en una resolución judicial en la que se haya realizado la debida ponderación en todas sus facetas, marcadas por Alexy y adoptadas por nuestro máximo tribunal, es decir la racionalidad, idoneidad y proporcionalidad, al respecto la Corte ha dicho que: "Conforme a la teoría de los principios, cuando dos derechos fundamentales o principios entran en colisión, los juzgadores deben resolver el problema atendiendo a las

$30 \quad$ PRUEBA PERICIAL EN GENÉTICA EN EL DELITO DE VIOLACIÓN, AD 608/2010, Segundo Tribunal Colegiado de Circuito del Centro Auxiliar de la $4^{\mathrm{a}}$ Región, 7 de octubre de 2010.

31 STS 651/2003 - ECLI:ES:TS: 2003:651, Recurso de Casación 153/2002, No. de resolución 107/2003, Tribunal Supremo, Sala de lo Penal, Madrid, de febrero de 2003. 
características del caso concreto, ponderando cuál de ellos debe prevalecer y tomando en cuenta tres elementos: I) La idoneidad; II) La necesidad y III) La proporcionalidad. El primero se refiere a que el principio adoptado como preferente sea el idóneo para resolver la controversia planteada; el segundo consiste en que la limitación de cierto principio sea estrictamente necesaria e indispensable, es decir, no debe existir alternativa que sea menos lesiva; y el tercer elemento se refiere a que debe primar el principio que ocasione un menor daño en proporción al beneficio correlativo que se dé u obtenga para los demás, en otras palabras, cuanto mayor sea el grado de no cumplimiento o de afectación de un principio, tanto mayor debe ser la importancia del cumplimiento del otro". ${ }^{32}$

Quedando, en consecuencia, muy claro que un punto esencial en cuanto a la responsabilidad del juzgador en la materia, lo es, sin duda, el cuidar la proporcionalidad en las medidas restrictivas de los derechos humanos al practicar las intervenciones corporales, la cual podemos conceptuar como "el parámetro decisivo para juzgar sobre la legitimidad constitucional de las medidas restrictivas de los derechos fundamentales." ${ }_{33}$

Otro punto esencial, sin duda, lo es el que el tribunal español determina la imposibilidad de obligar al imputado por la vía de la fuerza física a permitir la práctica de la prueba, por estimarla restrictiva de los derechos humanos del imputado y por consecuencia en España el criterio prevaleciente, a diferencia de México, es que no se puede realizar de esta forma.

Estimamos que una sana interpretación de nuestra legislación llevaría a la misma conclusión, ya que arribar a la justificación de violentar con la fuerza física al imputado para obtener la muestra sería equiparable a validar otras actuaciones obtenidas de esta forma, lo cual de forma alguna puede ir en consonancia con la salvaguarda de los derechos humanos en el proceso. Empero, existen tribunales constitucionales que sí justifican tales medidas, y doctrinarios que las avalan así De Luca ha dicho que: ${ }^{34}$

TEORÍA DE LOS PRINCIPIOS. SUS ELEMENTOS. Novena Época, Registro: 177124, Tribunales Colegiados de Circuito, tesis Aislada Semanario Judicial de la Federación y su Gaceta Tomo XXII, septiembre de 2005, Materia(s): Común, Tesis: I.4o.A.60 K, Página: 1579 Cuarto Tribunal Colegiado en materia Administrativa del Primer Circuito. Incidente de suspensión (revisión) 247/2005. Investigación Farmacéutica, S.A. de C.V. 13 de julio de 2005. Unanimidad de votos. Ponente: Jean Claude Tron Petit. Secretaria: Sandra Ibarra Valdez.

33 AAVV: Derecho Procesal Penal. Escuela Nacional de la Judicatura, Sto. Domingo, República Dominicana, 2006. p. 112.

34 DE LUCA, Javier Augusto: "Pruebas sobre el cuerpo del imputado o testigos y las garantías constitucionales”. En: III Seminario Interdisciplinario sobre Derecho a la Identidad 
La cláusula que proscribe la autoincriminación compulsiva suele ser vista como un primer obstáculo para la extracción de sangre o tomas de muestras contra la voluntad expresa o presunta del sujeto. Sin embargo, desde antiguo en los Estados Unidos de América -cuya Constitución ha sido molde de la Argentina- la interpretación de esta garantía ha sido que la Ley Fundamental prohíbe el uso de compulsión física o moral para obtener comunicaciones o expresiones de una persona, pero no excluye al cuerpo como evidencia cuando esta es material. La evidencia si es material resulta apta o competente (Corte de E.E.U.U., 218 U.S. 245). La voluntad del sujeto sobre el que recaerá el examen no es relevante, tanto si se niega como si está inconsciente, porque el privilegio protege a una persona sólo de verse obligada a testificar contra sí misma o de proveerle al Estado de alguna otra prueba de naturaleza testimonial o comunicativa. Su participación como donante es irrelevante respecto del resultado que depende exclusivamente de análisis químico (Corte de E.E.U.U., 384 U.S. 757). Por su parte, la Corte argentina dijo hace tiempo que un reconocimiento del imputado "no está comprendido en los términos de la cláusula que veda la exigencia de "declarar contra sí mismo" ni es colorario(sic) de la exención postulada de producir otra prueba incriminatoria. Ello, tanto porque la presencia del imputado en las actuaciones del proceso no es "prueba" en el sentido de la norma del caso, cuanto porque constituye corriente y razonable ejercicio de la facultad estatal investigatoria de los hechos delictuosos" y, siguiendo a la jurisprudencia norteamericana, dijo "que la cláusula que proscribe la autoincriminación no requiere la exclusión de la presencia física del acusado como prueba de su identidad, como no impide la obtención y el uso de las impresiones digitales" (Fallos: 255:18 "Cincotta", del 13 de febrero de 1963).

La doctrina, al igual que los tribunales, se ha dividido en sus opiniones, al respecto, Álvarez de Neyra opina que debemos tener presente que los derechos humanos no son absolutos, y que si bien la constitución -en este caso habla de la española- no establece límites al derecho a la intimidad y a la integridad física, estos pueden ser limitados ya por la voluntad de su titular al consentir la prueba o por la del juzgador cuando este se niegue, resultando válido que dicho consentimiento sea suplido por el juez. ${ }^{35}$

\footnotetext{
y Derechos Humanos, 25 y 26 de marzo, 2004, Buenos Aires, Argentina, disponible en: http:// www.abuelas.org.ar/material/ juridica/ seminario 3 04 htm \# anota7.

35 ÁLVAREZ DE NEYRA KAPPLER Susana: "El consentimiento en la toma de muestras de ADN. Especial referencia a los procesos de menores". En: Revista de Derecho y Genoma Humano, No. 34, 2011. pp. 51-97.
} 
Más a profundidad sobre esta disyuntiva, Romeo Casabona asegura que el problema es determinar si la resolución judicial genera una obligación para su destinatario o si, por el contrario, se trata de una carga procesal, en el primer supuesto, añade, es válido ejercer la coacción, pero en el segundo se tratará meramente de un indicio de culpabilidad. ${ }^{36}$

En cuanto a los derechos que pueden colisionar, García Fernández y Yurrebaso nos dicen que esencialmente el derecho a la intimidad, el derecho a la tutela judicial efectiva y derecho al debido procedimiento con respeto a todas las garantías judiciales; ${ }^{37}$ sin embargo, tales derechos, a juicio de los referidos autores, no se veían violentados si mediaba la autorización del juez, criterio que ha prevalecido a la fecha, empero si esta no se obtiene, es de explorado derecho que la prueba será ilícita, lo anterior se ve fortalecido por la sentencia del Tribunal Constitucional Español 501/2005 ${ }^{38}$, donde el criterio jurisprudencial estima que el hecho de que la obtención de la muestra, en este caso el esputo arrojado por el imputado al piso de la celda, violentaba el debido proceso y estimó tal prueba como ilícita.

Empero tal precedente fue modificado con posterioridad por el Tribunal Supremo en un caso similar y confirmado el fallo por el Tribunal Constitucional en un caso de terrorismo, ${ }^{39}$ al estimar este último que, si bien el derecho a la intimidad había sido afectado, tal afectación no era significativa pese a la ausencia de autorización judicial para la recolección de la muestra, toda vez que: "[...] Constatado que la realización del análisis del ADN del demandante de amparo supuso una injerencia en su derecho a la intimidad por su mera puesta en riesgo, hemos de analizar si tal injerencia se ha producido o no de forma constitucionalmente conforme. [...] la específica prueba pericial consistente en la obtención del ADN del demandante a partir de su saliva se produjo con la finalidad de ser comparado con el obtenido a partir de la muestra biológica hallada en una manga utilizada en la realización de un hecho delictivo, y tenía por objeto

36 ROMEO CASABONA, Carlos María y MALANDA, Sergio Romeo: Los identificadores de ADN en el sistema de justicia penal. Aranzadi-Thomson Reuters, Pamplona, 2010. p. 194.

37 GARCÍA FERNÁNDEZ, Oscar y YURREBASO, Iñaki: "Problemática de la recogida de estigios biológicos”. En: Casado, María y Guilén, Margarita: ADN forense: Problemas éticos y jurídicos. Ediciones de la Universidad de Barcelona/UNESCO, Barcelona, 2014. pp. 219-240.

38 STS 501/2005 de 19 de abril, Sala Segunda.

39 Pleno. Sentencia 199/2013, de 5 de diciembre de 2013. Recurso de amparo 95302005, Tribunal Constitucional, Publicado en: «BOE» núm. 7, de 8 de enero de 2014, páginas 55 a 85. 
el descubrimiento de la persona que había utilizado la mencionada manga en la perpetración de unos hechos delictivos de notable gravedad como lo son los de daños terroristas por los que finalmente fue condenado el demandante. De ahí que no quepa dudar de la concurrencia del fin legítimo en la medida adoptada por la policía judicial. [...] su práctica se acomoda con naturalidad a la finalidad para la que las atribuciones policiales son conferidas por el legislador, esto es, para la averiguación de los delitos $\mathrm{y}$ la puesta a disposición judicial de sus presuntos autores; $\mathrm{y}$, finalmente porque la menor intensidad de la injerencia en el derecho fundamental, [...], admite una relativa relajación de las exigencias de taxatividad en la norma que presta cobertura a aquella exigida por el Convenio europeo de derechos humanos. [...]En el presente caso concurren circunstancias excepcionales que permiten concluir que aun cuando el análisis de ADN efectuado no fuera ordenado judicialmente, no se lesionó el derecho del demandante a la intimidad personal".

Como vemos, tampoco existe un criterio definido al respecto, porque de lo inserto pareciera desprenderse que ante los delitos graves el tribunal se vuelve permisivo en cuanto a la intromisión en la esfera de derechos fundamentales del imputado, aún sin la respectiva autorización judicial, empero debemos apuntar en descargo del mismo que se trata de muestras abandonadas por el imputado, pero no existe precedente de justificación a partir de la sentencia del 2005 en que se justifique ni por el Tribunal Supremo ni por el Constitucional la obtención por la vía de la fuerza física de tales muestras.

En cuanto a la valoración de tales pruebas, en principio, resulta esencial que el juzgador distinga, dice, Vásquez-Rojas parafraseando a Michael y Adler, ${ }^{40}$ entre la cualidad de "ser probatorio" ("probativity") y la calidad de "ser probatorio". Una proposición es o no-es probatoria y, si lo es, entonces lo es en mayor o menor grado - lo que identifican como "fuerza probatoria"-. La cualidad de ser probatorio es la relevancia: "una proposición es relevante con independencia de cuán lejana pueda estar en una serie de proposiciones probatorias; en ese caso, se puede hablar de una 'proposición remotamente relevante', donde 'remoto' califica a la proposición y no a su relevancia”.

$40 \quad$ Michael, Jerome y Adler Mortimer J., The Nature of Judicial Proof: An Inquiry into Logical, Legal, and Empirical Aspects of the Law of Evidence, A D Press, 1931, pp. 95 y ss., citados por VÁSQUEZ-ROJAS, Carmen: "Sobre la cientificidad de la prueba científica en el proceso judicial". En: Anuario de Psicología Jurídica 2014, Universidad de Girona, España, 2014. pp. 65-73 
Añade el precitado autor, que, en consecuencia, deviene en válido inquirirse cuáles son las condiciones para que el juez estime como fiable una prueba científica, ya que como bien indica la autora, en múltiples ocasiones la doctrina jurídica utiliza de manera indistinta fiabilidad, credibilidad, autenticidad y validez, cuando es claro que tales vocablos presentan distintas connotaciones. ${ }^{41}$

Aunado a lo anterior, el hecho de que el operador judicial, como bien indica Coderch, debe tomar en consideración que cuando el legislador alude específicamente a "conocimientos científicos o tecnológicos, exigen un plus adicional a los saberes generales que se presuponen en el Tribunal y los específicos que caracterizan al conocimiento y aplicación del derecho, al oficio del jurista". ${ }^{42}$ Lo anterior nos permite arribar a la conclusión de que en la valoración de tales pruebas el juzgador debe ser cuidadoso no solo en su manejo jurídico, sino que deberá introducir baremos diversificados que le permitan establecer la fiabilidad de la prueba y que no necesariamente tendrán que ajustarse a los emitidos por los peritos, como claramente se desprende de nuestra propia legislación de la materia.

Empero, partiendo del artículo sexto de la Convención Universal de Derechos Humanos, el juzgador debe responsabilizarse de la aplicación del debido proceso en los términos que la propia convención marca, y no se puede dejar según Pastor Ridruejo, ${ }^{43}$ al arbitrio de cada estado como interpretar esta protección ya que: "[E]s obvio que si estas expresiones fuesen interpretados atendiendo al Derecho interno de cada Estado demandado, y teniendo en cuenta el distinto alcance y amplitud que poseen en cada uno de ellos, el nivel de protección ofrecido por la Convención carecería de uniformidad. Sería distinto para cada Estado demandado, lo cual es incompatible con los principios inspiradores del sistema. Para evitar esta consecuencia indeseable, el Tribunal no solo toma en consideración el Derecho interno del Estado demandado y los de los otros Estados parte en la Convención, sino sobre todo y principalmente el sentido que él mismo atribuye de modo autónomo a las definiciones convencionales. Es decir, el Tribunal se siente obligado

\footnotetext{
$41 \quad$ Ibíd, p. 67.

42 CODERCH, Salvador y PUIG, Antoni Rubí: "Riesgos de desarrollo y evaluación judicial del carácter científico de dictámenes periciales”. En: In Dret, Universitat Pompeu Fabra, Barcelona, 2008, disponible en: http://www.indret.com/pdf/519 es.pdf.

43 PASTOR RIDRUEJO, José Antonio: "La reciente jurisprudencia del Tribunal Europeo de Derechos Humanos", pp. 239-276, disponible en: http://www.ehu.eus/ cursosderechointernacionalvitoria/ponencias /pdf/2007/2007_8.pdf.
} 
a mirar más allá de las apariencias y a profundizar en el análisis de la realidad del procedimiento nacional en cuestión".

\section{Conclusiones.}

La prueba materia de nuestro estudio, si bien acarrea dificultades en su valoración, ello no es óbice para que el juzgador la deje de lado, por el contrario, como elemento indispensable dentro del proceso con toda su carga de veracidad, requiere además del respeto a los estándares de prueba que la doctrina y la propia legislación han ido construyendo, como ha evidenciado Taruffo, ${ }^{44}$ nos patentizan la necesidad de construir modelos conceptuales y lógicos, los cuales deben ser desarrollados por los juristas y epistemólogos, para así poder encarar apropiadamente una acertada decisión sobre el uso y aplicación de la ciencia en el contexto del proceso.

En otro orden de ideas y en cuanto a las decisiones del juez para la protección de los derechos humanos, estimamos que la aplicación forzosa de la prueba no puede justificarse en el marco de dicha tutela, aun cuando se trate del imputado, esto lleva sustento en las propias contradicciones de la ley que nos permiten arribar a que el legislador no le apuesta a tales medidas y a lo que la doctrina jurídica sostiene al respecto, sin obviar que hay doctrinarios que la defienden y estiman su procedencia con autorización judicial, pero en tales sustentos doctrinarios nunca se ha hablado de justificar el uso de la vis compulsiva al grado de violentar físicamente al imputado.

En cuanto a la valoración de la prueba, hemos dejado constancia de que nuestro máximo tribunal estima que dicha prueba es sui generis, y, en consecuencia, requiere de una valoración diversificada que no puede ser taxativa ya que implica en consecuencia baremos que inciden en conocimientos científicos ajenos al quehacer del juez que requieren que este determine el grado de fiabilidad que en un momento dado puede conferirle al perito.

La resolución de estos temas no cuenta con una regulación o jurisprudencia exhaustivas, que le permitan al juez edificar a partir de estos sus resoluciones, por lo que su papel como intérprete del derecho cobra especial relevancia para la toma de tales decisiones que de suyo no resultan nada sencillas, en ellas deberemos confiar en la experiencia y ponderación

44 TARUFFO, Michele: La prueba. Artículos y conferencias. Editorial Metropolitana, Santiago de Chile, 2009. p. 120. 
del juzgador en la búsqueda de resoluciones justas, pero indudablemente una regulación adecuada abonaría mucho más a la salvaguarda de los derechos humanos de quienes se ven sometidos a estas pruebas científicas, particularmente cuando ello se realiza por la vis compulsiva.

\section{Bibliografía}

ÁLVAREZ DE NEYRA KAPPLER, Susana: "El consentimiento en la toma de muestras de ADN Especial referencia a los procesos de menores". En: Revista de Derecho y Genoma Humano, No. 34, 2011. pp. 51-97.

ALSINA, Hugo: Tratado teórico práctico del derecho procesal civil y comercial, t. III. EDIAR, Buenos Aires, 1961.

ARELlano GARCÍA, Carlos: Derecho Procesal Civil. Porrúa, México, 1998

AAVV: Derecho Procesal Penal. Escuela Nacional de la Judicatura, Sto. Domingo, República Dominicana, 2006.

CALAMADREI, Piero: Elogio a los jueces escrito por un abogado. SENTIS, Santiago y MEDINA, Isaac J. (trad.). Ed. Reus, Madrid, 2009.

COBOS, Amalia Patricia: “Aspectos epistemológicos de las pruebas periciales genéticas". En: Estudio Comparado entre España y México. Universidad Autónoma de Chihuahua, 2015.

CODERCH, Salvador y PUIG, Antoni Rubí: "Riesgos de desarrollo y evaluación judicial del carácter científico de dictámenes periciales”. En: In Dret, Universitat Pompeu Fabra, 2008. Disponible en: http://www.indret. com/pdf/519_es.pdf.

CONTRERAS VACA, Francisco José: Derecho procesal civil, v. I. Oxford, México, 1999.

DE LUCA, Javier Augusto: "Pruebas sobre el cuerpo del imputado o testigos y las garantías constitucionales". En: III Seminario Interdisciplinario sobre Derecho a la Identidad y Derechos Humanos, 25 y 26 de marzo, 2004, Buenos Aires, Argentina. Disponible en: http://www.abuelas.org.ar/ material/ juridica/ seminario 3 _ 04 .htm \# anota7

DEVIS ECHANDÍA, Hernando: Teoría general de la prueba judicial, t. I,

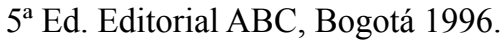


FERRER Jordi, et al: Estudios sobre la prueba. Fontamara, $3^{\text {a }}$ Ed., México, 2016.

FIGUEROA, Carmen, (Coord.): La prueba pericial cientifica. Instituto Universitario de Investigación en Ciencias Policiales/Universidad de Alcalá, Madrid, 2012.

GARCÍA FERNÁNDEZ, Oscar y YURREBASO, Iñaki: "Problemática de la recogida de estigios biológicos". En: Casado, María y Guilén, Margarita: ADNforense: Problemas éticos y jurídicos. Ediciones de la Universidad de Barcelona/UNESCO, Barcelona 2014. pp. 219-240

GÓMEZ DEL CASTILLO Y GÓMEZ, Manuel M.: “Aproximación a los nuevos medios de prueba en el proceso civil". En: Derecho y Conocimiento, v. I. Universidad de Huelva, 2001. pp. 77-90.

GONZÁLEZ-CUÉLLAR SERRANO, Nicolás: Proporcionalidad y derechos fundamentales en el proceso penal. Colex Editorial, Madrid, 1990.

GONZÁLEZ PILLADO, Esther e IGLESIAS CANLE, Inés: "La prueba pericial en la nueva ley de enjuiciamiento civil". En: Revista Xurídica Galega, No. 27, 2000. pp. 307-344.

LUCA, Stefano de, NAVARRO, Fernando y CAMERIERE, Roberto: "La prueba pericial y su valoración en el ámbito judicial español”. En: Revista Electrónica de Ciencia Penal y Criminología. [en línea], No. 15, 2013, disponible en: http://criminet.ugr.es/recpc/15/recpc15-19.pdf.

MARTÍN ALONSO, Francisco: "Recogida de muestras biológicas para la obtención de un perfil ADN, desde la perspectiva policial”. En: Noticias Jurídicas [en línea], mayo de 2014, disponible en: http://noticias.juridicas. Com/articulos/65-Derecho-Procesal-Penal/201405-recogida-de-muestras -biologicas.htm

MICHAEL, Jerome y ADLER Mortimer J.: The Nature of Judicial Proof: An Inquiry into Logical, Legal, and Empirical Aspects of the Law of Evidence. A D Press, 1931.

MIDÓN, Marcelo Sebastián: Derecho probatorio. Parte general, v. I. Ediciones Jurídicas Cuyo, Mendoza, 2007. 
PASTOR RIDRUEJO, José Antonio: La reciente jurisprudencia del Tribunal Europeo de Derechos Humanos. disponible en: http://www.ehu. eus/cursosderecho internacionalvitoria/ponencias /pdf/ 2007 / 2007_8.pdf PEREIRA CAMPOS, Santiago: Desafios y riesgos del derecho procesal contemporáneo. Instituto Chileno de Derecho Procesal, diciembre de 2012, disponible en: http://www.ichdp.cl/desafios-y-riesgos-del-derechoprocesal-contemporaneo/

RAMÍREZ, Diana María: "Los límites constitucionales a los poderes de oficio que tiene el juez sobre la prueba". En: Temas Procesales, No. 27, segundo semestre de 2011. COMLIBROS, Medellín. pp. 101-134.

ROMEO CASABONA, Carlos María y MALANDA, Sergio Romeo: Los identificadores de ADN en el sistema de justicia penal. Aranzadi-Thomson Reuters, Pamplona, 2010.

TARUFFO, Michele: La prueba. Artículos y conferencias. Editorial Metropolitana, Santiago de Chile, 2009.

VÁSQUEZ-ROJAS Carmen: "Sobre la cientificidad de la prueba científica en el proceso judicial". En: Anuario de Psicología Jurídica 2014, Universidad de Girona, España, 2014. pp. 65-73

\section{Legislación y Fallos judiciales}

CÓDIGO FEDERAL DE PROCEDIMIENTOS CIVILES

CÓDIGO NACIONAL DE PROCEDIMIENTOS PENALES

CONTRADICCIÓN DE TESIS 154/2005-PS de la que derivó la jurisprudencia 1a./J. 101/2006, publicada en el Semanario Judicial de la Federación y su Gaceta, Novena Época, Tomo XXV, marzo de 2007, página 111

CONTRADICCIÓN DE TESIS 50/2011. ENTRE LAS SUSTENTADAS POR LOS TRIBUNALES COLEGIADOS PRIMERO Y SEGUNDO, AMBOS EN MATERIA CIVIL DEL SÉPTIMO CIRCUITO. Número de registro: 23101 Novena Época, Primera Sala, Semanario Judicial de la Federación y su Gaceta, Tomo XXXIV, septiembre de 2011, p. 664

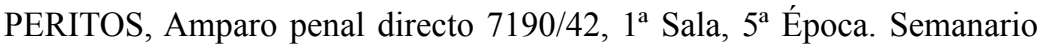
Judicial de la Federación, T. LXXV 
Pleno. Sentencia 199/2013, de 5 de diciembre de 2013. Recurso de amparo 9530-2005, Tribunal Constitucional

PRUEBA PERICIAL EN GENÉTICA EN EL DELITO DE VIOLACIÓN, AD 608/2010, Segundo Tribunal Colegiado de Circuito del Centro Auxiliar de la $4^{\text {a }}$ Región, 7 de octubre de 2010

PRUEBA PERICIAL EN GENÉTICA MOLECULAR. CUANDO SE OFRECE EN EL JUICIO DE DESCONOCIMIENTO DE PATERNIDADY EL MENOR SE NIEGA A QUE SE LE PRACTIQUEN LOS EXÁMENES CORRESPONDIENTES, DEBEN TENERSE POR CIERTOS LOS HECHOS NARRADOS POR SU CONTRAPARTE, SALVO PRUEBA, AD 226/2006, Tercer Tribunal Colegiado del Primer Circuito, 13 de julio de 2006.

STS 501/2005 de 19 de abril, Sala Segunda

STS 651/2003, Recurso de Casación 153/2002, No. de resolución 107/2003, Tribunal Supremo, Sala de lo Penal, Madrid, de febrero de 2003.

TEORÍA DE LOS PRINCIPIOS. SUS ELEMENTOS. Novena Época, Registro: 177124, Tribunales Colegiados de Circuito, tesis Aislada Semanario Judicial de la Federación y su Gaceta Tomo XXII, septiembre de 2005, Materia(s): Común, Tesis: I.4o.A.60 K, Página: 1579 Cuarto Tribunal Colegiado en materia Administrativa del Primer Circuito. Incidente de suspensión (revisión) 247/2005. Investigación Farmacéutica, S.A. de C.V. 13 de julio de 2005. Unanimidad de votos. Ponente: Jean Claude Tron Petit. Secretaria: Sandra Ibarra Valdez. 
